\title{
Hypoadiponectinemia and the presence of metabolic syndrome in patients with chronic kidney disease: results from the KNOW-CKD study
}

\author{
Chang-Yun Yoon ${ }^{1}$, Yung Ly Kim¹', Seung Hyeok Han ${ }^{1}$, Tae-Hyun Yoo ${ }^{1}$, Su-Ah Sung ${ }^{2}$, Woo-kyung Chung ${ }^{3}$, \\ Dong-Wan Chae ${ }^{4}$, Yong-Soo Kim ${ }^{5}$, Curie Ahn ${ }^{6}$ and Kyu Hun Choi ${ }^{*}$
}

\begin{abstract}
Background: In patients with chronic kidney disease, metabolic syndrome has been demonstrated to be the culprit behind diverse complications. Adiponectin is known to have anti-atherogenic and cardio-protective effects. Meanwhile, the relationship between adiponectin and metabolic syndrome in patients with chronic kidney disease has not been clarified. The aim of this study was to elucidate the relationship between adiponectin level and metabolic syndrome in patients with chronic kidney disease.

Methods: The KoreaN Cohort Study for Outcome in Patients with Chronic Kidney Disease is a cohort study that enrolled subjects with chronic kidney disease throughout South Korea. From February 2011 to July 2014, data were collected from 1332 patients with chronic kidney disease.

Results: The mean age of the patients was 53.5 years and 803 patients (60.7\%) were men. The median adiponectin level was $10.7 \mathrm{\mu g} / \mathrm{mL}$ and 585 (44.3\%) patients had metabolic syndrome. In multiple linear regression analysis, log adiponectin was positively associated with high-density lipoprotein cholesterol levels $(\beta=0.006)$, whereas it was negatively associated with serum albumin $(\beta=-0.284)$, triglyceride $(\log \beta=-0.288)$, high sensitivity C-reactive protein (log $\beta=-0.058)$ levels and estimated glomerular filtration rate $(\beta=-0.005)$. Multiple logistic regression analysis indicated that low adiponectin level was independently associated with a higher risk of metabolic syndrome (per $1 \mu \mathrm{g} / \mathrm{mL}$ increase; odds ratio $=0.953,95 \%$ confidence interval $=0.898-0.970, P<0.001$ ) after adjustment for multiple confounding factors.
\end{abstract}

Conclusions: Hypoadiponectinemia is independently associated with the presence of metabolic syndrome in patients with chronic kidney disease.

Keywords: Adiponectin, Chronic kidney disease, Metabolic syndrome

\section{Background}

Metabolic syndrome is defined as the aggregation of non-traditional risk factors, including central obesity, hypertension, hyperglycemia, hypertriglyceridemia, and

\footnotetext{
*Correspondence: khchoi6@yuhs.ac

${ }^{1}$ Department of Internal Medicine, College of Medicine, Institute

of Kidney Disease Research, Yonsei University, 50 Yonsei-ro,

Seodaemun-gu, Seoul 120-752, Republic of Korea

Full list of author information is available at the end of the article
}

decreased high-density lipoprotein cholesterol (HDL-C) [1]. The clinical significance of metabolic syndrome is its association with endocrinologic derangement, cardiovascular events [2], and renal impairment [3] in the general population. In addition, unfavorable clinical relationships were also reported in patients with chronic kidney disease on maintenance dialysis [4].

Adiponectin, which is released from adipocytes [5], is known to have anti-atherogenic and cardio-protective effects. It is chiefly related to insulin resistance and 
systemic inflammation, which are important factors for non-traditional risks of adverse outcome in chronic kidney disease [6]. Hypoadiponectinemia is related to metabolic syndrome [7] and increased intima-media thickness, which is a well-known early indicator of atherosclerosis in the general population [8] and in patients with chronic kidney disease [9]. However, the relationship between adiponectin level and metabolic syndrome in patients with chronic kidney disease has not been definitely clarified [10]. Decreased estimated glomerular filtration rate (eGFR), which is a well-known risk factor of metabolic syndrome, is significantly and independently related to hyperadiponectinemia in patients with chronic kidney disease [11]. In addition, several medications affecting adiponectin level and metabolic derangements such as statins or fibrates were not considered in most previous research studies. Regarding the important impact on clinical outcomes of metabolic syndrome in patients with chronic kidney disease, clarification of the relationship between metabolic syndrome and adiponectin level is mandatory.

Therefore, the aim of this study is to clarify the determinant factors of adiponectin level, and elucidate the relationship between adiponectin level and metabolic syndrome in patients with chronic kidney disease.

\section{Methods}

\section{Subjects}

The study has a cross-sectional design, using the database system of the KoreaN Cohort Study for Outcome in Patients with Chronic Kidney Disease (KNOWCKD), a nationwide multicenter prospective cohort including chronic kidney disease stage 1-5 pre-dialysis patients from February 2011 to July 2014. KNOW-CKD was implemented to investigate the pathophysiologic mechanisms of renal or cardiovascular outcomes in Korean chronic kidney disease populations. The detailed design and methods of the KNOW-CKD were previously published [12]. Among 1528 patients, 73 patients were excluded due to unavailable eGFR or adiponectin data, and 133 patients were also excluded due to missing data on blood pressure, waist measurement, triglycerides, HDL-C, or glucose. A total of 1322 patients were included in the final analysis.

\section{Data collection}

All data analyzed in this study were collected at the time of enrollment. The demographic data were collected by experienced doctors and nurses from the study subjects. Body mass index was calculated as weight in kilograms divided by the square of height in meters [13], and the measurements of baseline blood pressure were performed in the clinic using an electronic sphygmomanometer. The use of medication at the time of enrollment was determined by a specialized nurse for KNOW-CKD in accordance with the study protocol.

A total $10 \mathrm{~mL}$ of whole blood was collected using a serum separation tube (SST) and centrifuged within $1 \mathrm{~h}$ after collection for the separation of serum prior to delivery to the central laboratory (Lab Genomics, Korea) for measuring creatinine. Laboratory data included complete blood cell counts, glucose, uric acid, blood urea nitrogen, serum creatinine, calcium and phosphate, lipid profiles, serum albumin, and high sensitivity $\mathrm{C}$-reactive protein (hs-CRP) level at the central laboratory. Serum creatinine was measured by an IDMS-traceable method. Calcium levels were corrected by using the serum albumin level. Another $15 \mathrm{~mL}$ of the first-voided urine was also collected to analyze urinary levels of albumin and creatinine at the central laboratory. Albuminuria was determined by urinary albumin-to-creatinine ratio (UACR) from spot urine samples, and eGFR was calculated using the fourvariable modification of diet in renal disease (MDRD) equation including age, sex, race, and serum creatinine level [14]. Plasma adiponectin (Adipogen AG, Liestal, Switzerland) was measured using enzyme-linked immunosorbent assays. The Adiponectin (human) ELISA Kit, which was used in analysis of KNOW-CKD cohort subjects, is a total adiponectin kit that detects the total level of low-, middle-, and high-molecular-weight adiponectin. Other methods were described in our previous study [12].

\section{Diagnosis of metabolic syndrome}

The harmonizing definition [1] bases the diagnosis of metabolic syndrome on the presence of three or more of the following: (1) waist circumference (abdominal obesity) $>89 \mathrm{~cm}$ in men or $>80 \mathrm{~cm}$ in women, (2) triglyceride $\geq 150 \mathrm{mg} / \mathrm{dL}$ or taking medication for dyslipidemia, (3) HDL-C $<40 \mathrm{mg} / \mathrm{dL}$ in men or $<50 \mathrm{mg} /$ $\mathrm{dL}$ in women or taking medication, (4) systolic blood pressure $\geq 130 \mathrm{mmHg}$ and/or diastolic blood pressure $\geq 85 \mathrm{mmHg}$ or taking medication for hypertension, (5) fasting glucose $\geq 100 \mathrm{mg} / \mathrm{dL}$ or taking medication for diabetes. Defining thresholds for abdominal obesity are based on the Asian population [15].

\section{Statistical analyses}

Continuous variables were represented by using mean \pm standard deviation or the median (interquartile range), while categorical variables were represented as the number of subjects (percentage). Normality of distribution was ascertained by the Kolmogorov-Smirnov test. To compare differences between patients with and without metabolic syndrome, Student's $t$ test or the MannWhitney $U$-test was used for continuous variables and 
the Chi-square test for categorical variables. Univariate and multiple linear regression analyses were performed to determine independent factors associated with adiponectin level. Regarding the distribution of variables, adiponectin level, triglyceride, hs-CRP, and UACR were transformed to natural logarithm values for linear regression analysis. The independent predictive role of adiponectin level for the presence of metabolic syndrome was confirmed by multiple logistic regression analysis, which included significant variables in the comparison of baseline characteristics according to the presence of metabolic syndrome and multiple linear regression analysis. For further investigation beyond multiple logistic regression analysis, a cubic spline model was developed to illustrate systemic relations between adiponectin level and the risk of metabolic syndrome. We also conducted baseline subgroup analyses stratified by cause of chronic kidney disease, sex, age, diabetes mellitus, body mass index, UACR, eGFR, statin use, and angiotensin II receptor blocker (ARB). The trend for the mean adiponectin level across the numbers of metabolic syndrome components was verified by the trend test. Statistical analysis was performed with IBM SPSS Statistics for Windows version 23.0 (IBM SPSS Inc., Chicago, IL, USA). P values less than 0.05 were considered significant.

\section{Results}

\section{Baseline characteristics according to the presence of metabolic syndrome}

The baseline characteristics are shown in Table 1 . The mean age of the study population was $53.5 \pm 12.4$ years and $803(60.7 \%)$ patients were men. There were 153 (11.6\%), 243 (18.4\%), 511 (38.7\%), 312 (23.6\%), and $103(7.8 \%)$ patients included in stage 1-5 chronic kidney disease groups, respectively. The mean eGFR value was $49.3 \pm 29.8 \mathrm{~mL} / \mathrm{min} / 1.73 \mathrm{~m}^{2}$, and the median adiponectin level was $10.7(6.2-17.8) \mu \mathrm{g} / \mathrm{mL}$. Metabolic syndrome was present in $585(44.3 \%)$ patients. Patients were divided into 2 groups according to the presence of metabolic syndrome. UACR [208 (45-533) vs. 398 (113$1557) \mathrm{mg} / \mathrm{g} \mathrm{Cr}]$ and hs-CRP $[0.05(0.02-0.18)$ vs. 0.12 (0.04-0.34) mg/dL] were higher, while eGFR $(53.7 \pm 30.9$ vs. $43.8 \pm 27.3 \mathrm{~mL} / \mathrm{min} / 1.73 \mathrm{~m}^{2}$ ) and adiponectin level [12.5 (7.1-19.6) vs. $8.6(5.3-14.9) \mu \mathrm{g} / \mathrm{mL}]$ were significantly lower in the metabolic syndrome group compared to the non-metabolic syndrome group.

Crude prevalence rates of metabolic syndrome, based on the combination of chronic kidney disease stages and quartilized adiponectin levels, are shown in Fig. 1. Cross-categorization was performed based on the combination of chronic kidney disease stages and quartilized adiponectin categories. Crude prevalence rates of metabolic syndrome were higher according to increased adiponectin levels in chronic kidney disease stage 1 [Q1 vs. Q4, 21 (45.7\%) vs. 2 (4.3\%)], 2 [47 (51.1\%) vs. 6 (6.5\%)], and stage 3 [80 (35.4\%) vs. $32(14.2 \%)]$ groups, but these correlations were blunted in stage 4 group. Furthermore, in stage 5 group, highest-level adiponectin group had the most number of subjects diagnosed with metabolic syndrome [5 (8.6\%) vs. $24(41.4 \%)]$.

\section{Relationship between clinical and biochemical variables and adiponectin level}

Univariate linear regression analysis was performed to determine the relationship between clinical and biochemical variables and the adiponectin level (Table 2). In the analysis, age $(\beta=0.005)$, phosphate $(\beta=0.284)$, total cholesterol (per $10 \mathrm{mg} / \mathrm{dL}, \beta=0.015$ ), HDL-C (per $10 \mathrm{mg} / \mathrm{dL}, \beta=0.116$ ), UACR (per $1 \log , \beta=0.088$ ), and diuretics $(\beta=0.141)$ were significantly positively related to adiponectin level, while sex (male, $\beta=-0.366$ ), smoking $(\beta=-0.224)$, body mass index $(\beta=-0.053)$, waist circumference $(\beta=-0.020)$, hemoglobin $(\beta=-0.159)$, serum albumin $(\beta=-0.572)$, glucose (per $10 \mathrm{mg} / \mathrm{dL}$, $\beta=-0.012)$, calcium $(\beta=-0.127)$, triglyceride (per $1 \log , \beta=-0.332$ ), hs-CRP (per $1 \log , \beta=-0.050)$, eGFR (per $10 \mathrm{~mL} / \mathrm{min} / 1.73 \mathrm{~m}^{2}, \beta=-0.066$ ), and fibrate $(\beta=-0.509)$ were negatively related with statistical significance.

To further clarify the independent association of adiponectin level with clinical and biochemical variables, multiple linear regression analysis was performed with the variables that had significant differences in the comparison of baseline characteristics according to the presence of metabolic syndrome and univariate linear regression analysis. In the analysis, waist circumference $(\beta=-0.020)$, hemoglobin $(\beta=-0.069)$, serum albumin $(\beta=-0.326)$, triglyceride (per 1 log, $\beta=-0.192$ ), HDL-C (per $10 \mathrm{mg} / \mathrm{dL}, \beta=0.097$ ), hs-CRP (per $1 \log , \beta=-0.053$ ), eGFR (per $10 \mathrm{~mL} / \mathrm{min} / 1.73 \mathrm{~m}^{2}$, $\beta=-0.056)$, and fibrate use $(\beta=-0.358)$ were independently related to adiponectin level.

\section{Adiponectin level is independently associated with the presence of metabolic syndrome}

The relationship between the presence of metabolic syndrome and adiponectin level was evaluated by multiple logistic regression analysis with adjustments for age, sex, smoking status, body mass index, hemoglobin, serum albumin, uric acid, phosphate, hs-CRP, UACR, and eGFR. In addition, the past history of coronary artery disease and cerebrovascular disease, and current medication with ARB, diuretics, statins, ezetimibe, and fibrates were also adjusted (Table 3). In the fully adjusted model, decreased adiponectin levels were still independently associated with the risk of metabolic syndrome 
Table 1 Baseline characteristics of subjects

\begin{tabular}{|c|c|c|c|c|}
\hline Variables & $\begin{array}{l}\text { Total } \\
n=1322\end{array}$ & $\begin{array}{l}\text { Without MS } \\
n=737(55.7 \%)\end{array}$ & $\begin{array}{l}\text { With MS } \\
n=585(44.3 \%)\end{array}$ & $P$ \\
\hline Age (years) & $53.5 \pm 12.4$ & $51.5 \pm 12.7$ & $56.1 \pm 11.5$ & $<0.001$ \\
\hline Sex, men (\%) & $803(60.7)$ & $430(58.3)$ & $373(63.8)$ & 0.045 \\
\hline Smoking (\%) & $645(48.8)$ & $335(45.5)$ & $310(53.0)$ & 0.006 \\
\hline BMI $\left(\mathrm{kg} / \mathrm{m}^{2}\right)$ & $24.4 \pm 3.4$ & $23.0 \pm 2.9$ & $26.1 \pm 3.2$ & $<0.001$ \\
\hline Waist (cm) & $87.1 \pm 9.7$ & $82.8 \pm 8.6$ & $92.6 \pm 8.3$ & $<0.001$ \\
\hline SBP (mmHg) & $128.0 \pm 16.3$ & $123.1 \pm 14.1$ & $134.1 \pm 17.0$ & $<0.001$ \\
\hline $\mathrm{DBP}(\mathrm{mmHg})$ & $76.8 \pm 11.3$ & $75.2 \pm 10.7$ & $78.8 \pm 11.6$ & $<0.001$ \\
\hline CKD stage (\%) & & & & $<0.001$ \\
\hline Stage 1 & $153(11.6)$ & $107(14.5)$ & $46(7.9)$ & \\
\hline Stage 2 & $243(18.4)$ & $151(20.5)$ & $92(15.7)$ & \\
\hline Stage 3 & $511(38.7)$ & $285(38.7)$ & $226(38.6)$ & \\
\hline Stage 4 & $312(23.6)$ & $149(20.2)$ & $163(27.9)$ & \\
\hline Stage 5 & $103(7.8)$ & $45(6.1)$ & $58(9.9)$ & \\
\hline Cause of CKD (\%) & & & & $<0.001$ \\
\hline Glomerulonephritis & $420(31.8)$ & $278(37.7)$ & $142(24.3)$ & \\
\hline Diabetes mellitus & $295(22.3)$ & $87(11.8)$ & $208(35.6)$ & \\
\hline Hypertension & $273(20.7)$ & $132(17.9)$ & $141(24.1)$ & \\
\hline PKD & $239(18.1)$ & $181(24.6)$ & $58(9.9)$ & \\
\hline \multicolumn{5}{|l|}{ Laboratory findings } \\
\hline Hemoglobin (g/dL) & $12.8 \pm 2.0$ & $12.9 \pm 1.9$ & $12.7 \pm 2.1$ & 0.303 \\
\hline Albumin (g/dL) & $4.19 \pm 0.40$ & $4.22 \pm 0.37$ & $4.15 \pm 0.43$ & 0.002 \\
\hline Glucose (mg/dL) & $107.6 \pm 36.0$ & $98.7 \pm 23.2$ & $118.7 \pm 45.0$ & $<0.001$ \\
\hline Uric acid (mg/dL) & $7.12 \pm 1.99$ & $6.85 \pm 1.94$ & $7.47 \pm 1.99$ & $<0.001$ \\
\hline Calcium (mg/dL) & $8.96 \pm 0.45$ & $8.95 \pm 0.43$ & $8.96 \pm 0.47$ & 0.766 \\
\hline Phosphate (mg/dL) & $3.70 \pm 0.66$ & $3.65 \pm 0.61$ & $3.78 \pm 0.71$ & $<0.001$ \\
\hline Cholesterol (mg/dL) & $173.8 \pm 37.5$ & $172.6 \pm 35.4$ & $175.4 \pm 39.9$ & 0.191 \\
\hline $\mathrm{TG}(\mathrm{mg} / \mathrm{dL})$ & $154.3 \pm 96.2$ & $113.8 \pm 57.8$ & $205.3 \pm 109.7$ & $<0.001$ \\
\hline $\mathrm{HDL}-\mathrm{C}(\mathrm{mg} / \mathrm{dL})$ & $49.6 \pm 15.8$ & $55.2 \pm 15.4$ & $42.7 \pm 13.5$ & $<0.001$ \\
\hline LDL-C (mg/dL) & $96.6 \pm 30.7$ & $96.5 \pm 29.4$ & $96.8 \pm 32.2$ & 0.889 \\
\hline hs-CRP (mg/dL) & $0.07(0.02-0.25)$ & $0.05(0.02-0.18)$ & $0.12(0.04-0.34)$ & $<0.001$ \\
\hline UACR $(\mathrm{mg} / \mathrm{g} \mathrm{Cr})$ & $273(65-793)$ & $208(45-533)$ & $398(113-1557)$ & $<0.001$ \\
\hline $\mathrm{eGFR}\left(\mathrm{mL} / \mathrm{min} / 1.73 \mathrm{~m}^{2}\right)$ & $49.3 \pm 29.8$ & $53.7 \pm 30.9$ & $43.8 \pm 27.3$ & $<0.001$ \\
\hline Adiponectin $(\mu \mathrm{g} / \mathrm{mL})$ & $10.7(6.2-17.8)$ & $12.5(7.1-19.6)$ & $8.6(5.3-14.9)$ & $<0.001$ \\
\hline Male & $9.1(5.2-15.4)$ & $10.5(5.9-17.1)$ & $7.7(4.7-13.4)$ & $<0.001$ \\
\hline Female & $13.1(8.1-21.1)$ & $14.4(9.6-22.5)$ & $10.8(7.0-17.9)$ & $<0.001$ \\
\hline $\mathrm{DM}$ & $10.5(5.8-19.1)$ & $13.4(7.6-23.2)$ & $8.0(5.2-12.4)$ & 0.001 \\
\hline Non-DM & $10.8(6.3-17.5)$ & $12.4(7.0-19.0)$ & $9.7(5.4-17.3)$ & $<0.001$ \\
\hline \multicolumn{5}{|l|}{ Co-morbidity, n (\%) } \\
\hline Hypertension & $1215(91.9)$ & $651(92.1)$ & $564(97.2)$ & $<0.001$ \\
\hline $\mathrm{DM}$ & $425(32.1)$ & $125(17.0)$ & $300(51.3)$ & $<0.001$ \\
\hline CVD & $114(8.6)$ & $53(7.2)$ & $61(10.4)$ & 0.037 \\
\hline CAD & $99(7.5)$ & $35(4.7)$ & 64 (10.9) & $<0.001$ \\
\hline PAD & $24(1.8)$ & $9(1.2)$ & $15(2.6)$ & 0.069 \\
\hline $\mathrm{CHF}$ & $11(0.8)$ & $4(0.5)$ & $7(1.2)$ & 0.194 \\
\hline Arrhythmia & $29(2.2)$ & $16(2.2)$ & $13(2.2)$ & 0.950 \\
\hline \multicolumn{5}{|l|}{ Medication, $n$ (\%) } \\
\hline ACEi & 166 (12.6) & $93(12.6)$ & $73(12.5)$ & 0.939 \\
\hline ARB & 1046 (79.1) & $562(76.3)$ & $484(82.7)$ & 0.004 \\
\hline Diuretics & $432(32.7)$ & $171(23.2)$ & 261 (44.6) & $<0.001$ \\
\hline
\end{tabular}


Table 1 continued

\begin{tabular}{|c|c|c|c|c|}
\hline Variables & $\begin{array}{l}\text { Total } \\
n=1322\end{array}$ & $\begin{array}{l}\text { Without MS } \\
n=737(55.7 \%)\end{array}$ & $\begin{array}{l}\text { With MS } \\
n=585(44.3 \%)\end{array}$ & $P$ \\
\hline Beta blocker & $368(27.8)$ & $142(19.3)$ & $226(38.6)$ & $<0.001$ \\
\hline Statin & $649(49.1)$ & $321(43.6)$ & $328(56.1)$ & $<0.001$ \\
\hline Ezetimibe & $95(7.2)$ & $42(5.7)$ & $53(9.1)$ & 0.019 \\
\hline Fibrate & $31(2.3)$ & $7(0.9)$ & $24(4.1)$ & $<0.001$ \\
\hline
\end{tabular}

MS metabolic syndrome, $B M I$ body mass index, SBP systolic blood pressure, $D B P$ diastolic blood pressure, $C K D$ chronic kidney disease, $P K D$, polycystic kidney disease, $T G$ triglyceride, $H D L-C$ high-density lipoprotein cholesterol, $L D L-C$ low-density lipoprotein cholesterol, $h s$ - $C R P$ high sensitivity $C$-reactive protein, UACR urine albuminto-creatinine ratio, eGFR estimated glomerular filtration rate, $D M$ diabetes mellitus, $C V D$ cerebrovascular disease, $C A D$ coronary artery disease, $P A D$ peripheral artery disease, $C H F$ congestive heart failure, $A C E i$ angiotensin converting enzyme inhibitor, $A R B$ angiotensin II receptor blocker

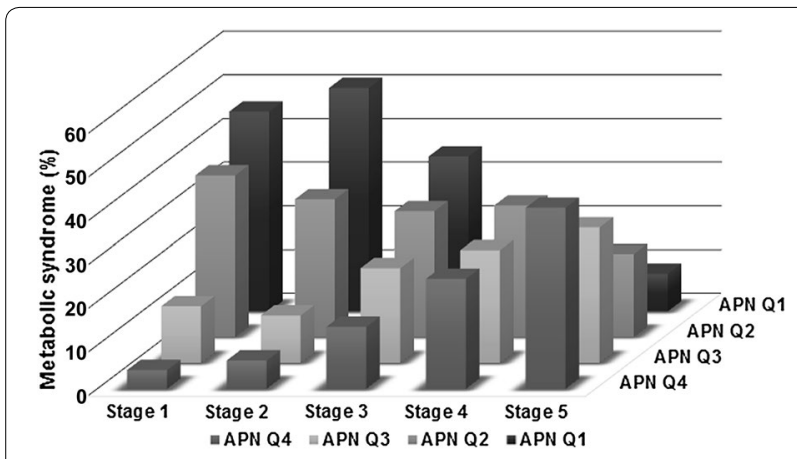

Fig. 1 Crude prevalence rates of MS in the 20 groups, based on the combination of CKD stages and quartilized APN levels. Cross-categorization was performed based on the combination of CKD stages and quartilized APN category. Crude prevalence rates of MS were higher according to increased APN levels in CKD stage 1 [Q1 vs. Q4, 21 (45.7\%) vs. $2(4.3 \%)]$, stage $2[47(51.1 \%)$ vs. $6(6.5 \%)]$, and stage 3 [80 (35.4\%) vs. 32 (14.2\%)] groups, but these correlations were blunted in stage 4. Furthermore, in stage 5 patients, group with the highest APN level had the most number of subjects diagnosed with metabolic syndrome [5 (8.6\%) vs. 24 (41.4\%)]. MS metabolic syndrome, CKD chronic kidney disease, APN adiponectin

in chronic kidney disease patients [adiponectin, $1 \mu \mathrm{g} /$ $\mathrm{mL}$ increase, odds ratio (OR), 95\% confidence interval $(C I)=0.956$ (0.937-0.976), $P<0.001]$. Furthermore, the independent association was still significant in diabetic [OR $(95 \% \mathrm{CI})=0.942(0.911-0.974), P<0.001]$ or nondiabetic [OR $(95 \% \mathrm{CI})=0.967(0.939-0.997), P=0.031]$ nephropathy after adjustment for multiple confounding variables. For a more specific explanation of non-diabetic groups, hypertensive and glomerulonephritis groups still showed independent association between high adiponectin levels and presence of metabolic syndrome, while polycystic kidney disease group did not show any significance in the full adjustment model (Table 4).

The results of the cubic splines graph illustrating the association between adiponectin levels and the risk of metabolic syndrome is shown in Fig. 2. A trend towards decreased association of metabolic syndrome was observed in chronic kidney disease patients with higher adiponectin levels. In addition, when the subjects were divided into 6 groups according to the number of metabolic syndrome components, the adiponectin level decreased as the number of components increased ( $P$ for the trend $<0.001$, Fig. 3).

\section{Discussion}

In the general population, adiponectin may decrease the risk for metabolic disturbance-related diseases such as obesity, type 2 diabetes, and metabolic syndrome [16]. However, there has been an apparent paradox regarding its diverse correlations contributing to unfavorable clinical implications, including cardiac dysfunction, pulmonary disease, and chronic kidney disease. Although several existing theories suggest such paradox, the exact mechanism of hyperadiponectinemia in these disease entities remains incomprehensible. In particular, high serum adiponectin levels predict mortality and progression to end-stage renal disease in patients with kidney disease [17]. Given the opposite results between hyperand hypoadiponectinemia on renal progression, cardiovascular outcomes, or metabolic disturbance-related disease, we have clarified the scope between circulating adiponectin levels and metabolic syndrome using a wellestablished chronic kidney disease cohort database. As a result, we clearly showed that hypoadiponectinemia was independently associated with the presence of metabolic syndrome, even after adjusting for multiple confounding factors including traditional risk factors, co-morbidities, and medication use.

In the present study, adiponectin level was negatively associated with eGFR, which is fairly consistent with previous investigations. Since the major clearance process of adiponectin occurs in the liver, explaining the exact mechanism of high adiponectin levels in low eGFR patients is not simple, and the causal relationship is unclear. In patients with chronic kidney disease, chronic inflammation, oxidative stress, and sympathetic overactivity are common clinical features, and these features might inhibit adiponectin expression [18]. However, the kidney has been regarded as a key organ for biodegradation of various proteins and cytokines; thus, decreased 
Table 2 Linear regression analysis for the association of adiponectin with clinical and biochemical variables

\begin{tabular}{|c|c|c|c|c|}
\hline \multirow[t]{2}{*}{ Variables } & \multicolumn{2}{|l|}{ Univariate } & \multicolumn{2}{|l|}{ Multiple } \\
\hline & $\beta(95 \% \mathrm{Cl})$ & $P$ & $\beta(95 \% \mathrm{Cl})$ & $P$ \\
\hline Age (per 1 year) & 0.005 (0.002 to 0.008$)$ & 0.004 & $0.002(-0.002$ to 0.005$)$ & 0.346 \\
\hline Sex (male) & $-0.366(-0.450$ to -0.283$)$ & $<0.001$ & $-0.067(-0.196$ to 0.061$)$ & 0.305 \\
\hline Smoking & $-0.224(-0.307$ to -0.141$)$ & $<0.001$ & $0.002(-0.111$ to 0.115$)$ & 0.975 \\
\hline Body mass index (per 1 kg/m²) & $-0.053(-0.065$ to -0.041$)$ & $<0.001$ & & \\
\hline Waist circumference (per 1 cm) & $-0.020(-0.024$ to -0.016$)$ & $<0.001$ & $-0.008(-0.013$ to -0.003$)$ & 0.002 \\
\hline Systolic blood pressure (per 10 mmHg) & $0.007(-0.019$ to 0.033$)$ & 0.584 & & \\
\hline Diastolic blood pressure (per 10 mmHg) & $-0.005(-0.042$ to 0.033$)$ & 0.811 & & \\
\hline \multicolumn{5}{|l|}{ Laboratory findings } \\
\hline Hemoglobin (per $1 \mathrm{~g} / \mathrm{dL}$ ) & $-0.159(-0.178$ to -0.139$)$ & $<0.001$ & $-0.069(-0.099$ to -0.039$)$ & $<0.001$ \\
\hline Albumin (per $1 \mathrm{~g} / \mathrm{dL}$ ) & $-0.572(-0.672$ to -0.473$)$ & $<0.001$ & $-0.326(-0.451$ to -0.202$)$ & $<0.001$ \\
\hline Glucose (per 10 mg/dL) & $-0.012(-0.024$ to -0.001$)$ & 0.041 & $-0.009(-0.021$ to 0.003$)$ & 0.130 \\
\hline Uric acid (per 1 mg/dL) & $0.014(-0.007$ to 0.036$)$ & 0.179 & & \\
\hline Calcium (per 1 mg/dL) & $-0.127(-0.220$ to -0.034$)$ & 0.008 & & \\
\hline Phosphate (per 1 mg/dL) & 0.284 (0.222 to 0.345$)$ & $<0.001$ & & \\
\hline Cholesterol (per 10 mg/dL) & 0.015 (0.004 to 0.026$)$ & 0.008 & & \\
\hline Triglyceride (per 1 log) & $-0.332(-0.408$ to -0.256$)$ & $<0.001$ & $-0.192(-0.283$ to -0.101$)$ & $<0.001$ \\
\hline HDL-C (per 10 mg/dL) & 0.116 (0.090 to 0.142) & $<0.001$ & 0.097 (0.066 to 0.128) & $<0.001$ \\
\hline LDL-C (per 10 mg/dL) & $0.009(-0.005$ to 0.023$)$ & 0.201 & & \\
\hline hs-CRP (per 1 log) $)^{\mathrm{a}}$ & $-0.050(-0.076$ to -0.024$)$ & $<0.001$ & $-0.053(-0.080$ to -0.026$)$ & $<0.001$ \\
\hline UACR (per $1 \log )^{\mathrm{a}}$ & 0.088 (0.062 to 0.113$)$ & $<0.001$ & 0.028 (-0.001 to 0.056$)$ & 0.055 \\
\hline eGFR (per 10 mL/min/1.73 m²) & $-0.066(-0.080$ to -0.052$)$ & $<0.001$ & $-0.059(-0.078$ to -0.041$)$ & $<0.001$ \\
\hline \multicolumn{5}{|l|}{ Co-morbidities } \\
\hline Diabetes mellitus & $0.018(-0.072$ to 0.108$)$ & 0.693 & & \\
\hline Hypertension & $-0.021(-0.175$ to 0.132$)$ & 0.786 & & \\
\hline Coronary artery disease & $0.071(-0.088$ to 0.230$)$ & 0.379 & & \\
\hline Peripheral artery disease & $0.116(-0.198$ to 0.429$)$ & 0.470 & & \\
\hline Cerebrovascular disease & $0.010(-0.139$ to 0.159$)$ & 0.897 & & \\
\hline Congestive heart failure & $-0.363(-0.823$ to 0.098$)$ & 0.122 & & \\
\hline Arrhythmia & $-0.156(-0.441$ to 0.130$)$ & 0.285 & & \\
\hline \multicolumn{5}{|l|}{ Medications } \\
\hline $\mathrm{ACEi}$ & $0.045(-0.082$ to 0.171$)$ & 0.490 & & \\
\hline ARB & $-0.089(-0.203$ to 0.024$)$ & 0.123 & & \\
\hline Diuretics & 0.141 (0.051 to 0.231$)$ & 0.002 & $0.042(-0.052$ to 0.137$)$ & 0.377 \\
\hline Beta blocker & $-0.059(-0.153$ to 0.035$)$ & 0.221 & & \\
\hline Statin & $-0.051(-0.135$ to 0.033$)$ & 0.236 & & \\
\hline Ezetimibe & $-0.081(-0.243$ to 0.081$)$ & 0.328 & & \\
\hline Fibrate & $-0.509(-0.785$ to -0.233$)$ & $<0.001$ & $-0.358(-0.627$ to -0.089$)$ & 0.009 \\
\hline
\end{tabular}

${ }^{a}$ Log transformed, adiponectin was also transformed by log

$H D L-C$ high-density lipoprotein cholesterol, $L D L-C$ low-density lipoprotein cholesterol, $h s$ - $C R P$ high sensitivity C-reactive protein, UACR urinary albumin-to-creatinine ratio, eGFR estimated glomerular filtration rate, $A C E i$ angiotensin converting enzyme inhibitor, $A R B$ angiotensin II receptor blocker

kidney function could promote the accumulation of adiponectin in the systemic blood. Although a counterregulatory hyperadiponectinemia in acute pathologic conditions such as full-blown nephrotic syndrome has been reported [19], the evidence showing decreased adiponectin levels after kidney transplantation regardless of serum creatinine level or insulin resistance also strengthens the former postulation [20]. In addition, the 'chronic' damaged kidney function and consequent uremic milieu also results in hyperadiponectinemia through the inhibition of adiponectin gene expression and the activation of the renin-angiotensin system [21]. Meanwhile, relatively lower adiponectin levels compared to previous studies that investigated the impact of 
Table 3 Adiponectin as a risk factor of metabolic syndrome

\begin{tabular}{llr}
\hline & \multicolumn{2}{l}{ Odds ratio (95\% confidence interval) } \\
\cline { 2 - 3 } & \multicolumn{1}{l}{ Total } & \multicolumn{1}{c}{$\boldsymbol{P}$} \\
\hline Crude & $0.966(0.954-0.978)$ & $<0.001$ \\
Model 1 & $0.983(0.969-0.997)$ & 0.015 \\
Model 2 & $0.961(0.946-0.977)$ & $<0.001$ \\
Model 3 & $0.959(0.940-0.979)$ & $<0.001$ \\
Model 4 & $0.956(0.937-0.976)$ & $<0.001$ \\
\hline
\end{tabular}

Adiponectin $1 \mu \mathrm{g} / \mathrm{mL}$ increase, subgroup analysis was performed according to the cause of chronic kidney disease

Model 1: adjusted for age, sex, smoking status, and body mass index

Model 2: adjusted for model 1 + hemoglobin, serum albumin, uric acid, and phosphate

Model 3: adjusted for model $2+$ hs-CRP, urinary albumin-to-creatinine ratio, and eGFR

Model 4: adjusted for model $3+$ coronary artery disease, cerebrovascular disease, ARB, diuretics, statin, ezetimibe, and fibrate

$D M$ diabetes mellitus, $h s-C R P$ high sensitivity C-reactive protein, eGFR estimated glomerular filtration rate, $A R B$ angiotensin II receptor blocker

adiponectin levels in patients with chronic kidney disease might be due to the difference of mean eGFR in the present study population [22].

Our study showed that UACR was positively associated with adiponectin level. Even though the adipocyte is the chief secretory organ of adiponectin, the kidney is a major target organ through the adiponectin receptors (Adipo R) 1 and 2 in the intra-renal arterioles, endothelium, podocytes, mesangial cells of the glomerulus, and proximal tubular cells [23]. In experimental studies, adiponectin knockout mice showed exacerbation of albuminuria and renal fibrosis, and the restoration of adiponectin showed normalization of albuminuria, improvement of podocyte foot process effacement, and reduced urinary and glomerular markers of oxidant stress in adiponectin knockout mice [24]. In addition, the renal expression of Adipo R1 and R2 in adenine-induced chronic kidney disease rats is significantly increased compared to controls, and positively related to the adiponectin level in serum or urine [25]. All things taken together including previous mentioned evidence, the adiponectin level is substantially increased in full-blown nephrotic syndrome compared to controls [19], and it can be postulated that adiponectin is increased for counter-regulatory or kidney-protective purposes in damaged kidneys, similar to albuminuria.

From the clinical aspect, a landmark study showed that high adiponectin levels are associated with a lower risk of myocardial infarction in men [26], and this was followed by several remarkable studies that showed that higher adiponectin levels are associated with favorable clinical outcomes [27]. The favorable adiponectin effect is independently associated with not only eGFR and albuminuria, but also all-cause mortality and cardiovascular events in chronic kidney disease [11]. However, with established chronic kidney disease, the inverse relationship is not generally implicated and the findings are more complicated. The paradoxical increase of adiponectin level in those with the highest mortality may have been secondary to weight loss, which is a known stimulator of adiponectin as well as an independent risk factor in end-stage renal or heart disease patients [28]. The expression of adiponectin receptor mRNA on peripheral blood mononuclear cells in end-stage renal disease patients on hemodialysis [29] is increased and significantly related to subcutaneous and visceral fat. These findings imply that the inverse relationship between adiponectin level and renal function could result from the resistance effect of adiponectin in patients with chronic uremia, thus the

Table 4 Subgroup analyses of relationship between adiponectin levels and presence of metabolic syndrome

\begin{tabular}{llllll}
\hline & \multicolumn{4}{l}{ Odds ratio (95\% confidence interval) } \\
\cline { 2 - 6 } & DM & Non-DM & & & \\
\cline { 3 - 6 } & & Total & HTN & GN & PKD \\
\hline Crude & $0.964(0.943-0.984)$ & $0.951(0.935-0.967)$ & $0.941(0.912-0.971)$ & $0.955(0.931-0.979)$ & $0.944(0.904-0.987)$ \\
Model 1 & $0.973(0.949-0.997)$ & $0.969(0.951-0.988)$ & $0.949(0.916-0.984)$ & $0.980(0.952-1.009)$ & $0.954(0.907-1.004)$ \\
Model 2 & $0.952(0.923-0.981)$ & $0.957(0.935-0.980)$ & $0.944(0.905-0.985)$ & $0.949(0.913-0.987)$ & $0.962(0.911-1.016)$ \\
Model 3 & $0.946(0.913-0.980)$ & $0.957(0.932-0.983)$ & $0.950(0.901-1.003)$ & $0.942(0.900-0.986)$ & $0.950(0.899-1.004)$ \\
Model 4 & $0.933(0.898-0.970)$ & $0.959(0.932-0.986)$ & $0.939(0.885-0.996)$ & $0.942(0.896-0.990)$ & $0.969(0.913-1.028)$ \\
\hline
\end{tabular}

Adiponectin $1 \mu \mathrm{g} / \mathrm{mL}$ increase, subgroup analysis was performed according to the cause of chronic kidney disease

Model 1: adjusted for age, gender, smoking status, and body mass index

Model 2: adjusted for model $1+$ hemoglobin, serum albumin, uric acid, phosphate, and parathyroid hormone

Model 3: adjusted for model $2+$ hs-CRP, urine albumin-to-creatinine ratio, and eGFR

Model 4: adjusted for model $3+$ coronary artery disease, cerebrovascular disease, ARB, diuretics, statin, ezetimibe, and fibrate

$D M$ diabetic mellitus, HTN hypertension, GN glomerulonephritis, PKD polycystic kidney disease, $h s$-CRP high sensitivity C-reactive protein, eGFR estimated glomerular filtration rate, $A R B$ angiotensin II receptor blocker 


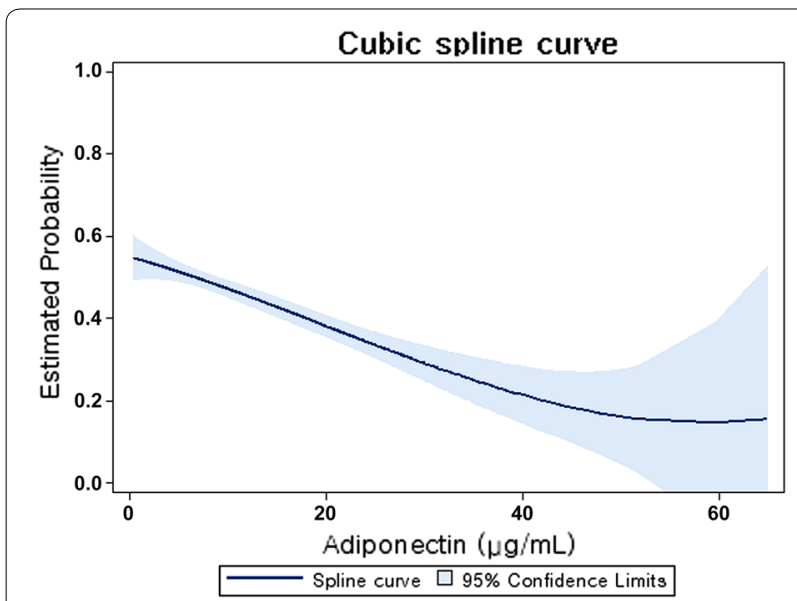

Fig. 2 Cubic spline regression models of the estimated probability (with 95\% confidence interval) of metabolic syndrome according to the adiponectin level. Multiple model adjusted for age, sex, smoking status, body mass index, hemoglobin, serum albumin, uric acid, phosphate, high sensitivity C-reactive protein, urinary albumin-tocreatinine ratio, estimated glomerular filtration rate, coronary artery disease, cerebrovascular disease, angiotensin II receptor blocker, diuretics, statin, ezetimibe, and fibrate

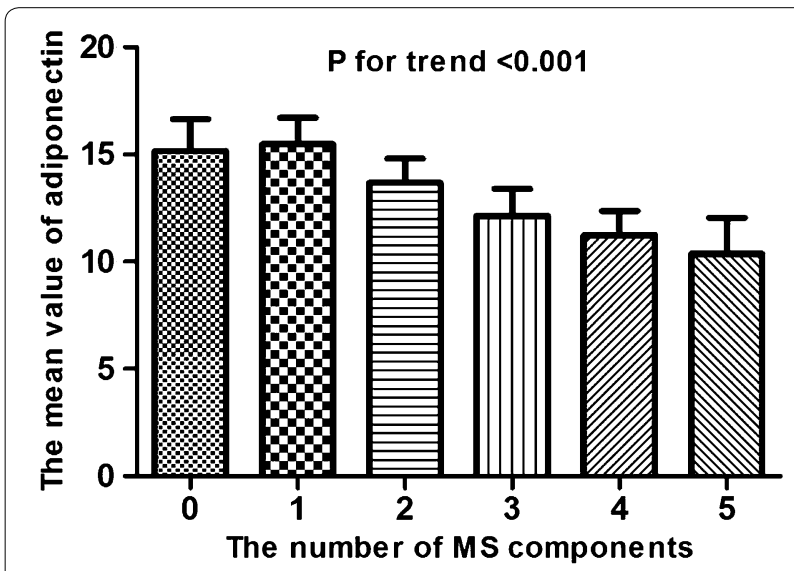

Fig. 3 The mean value of adiponectin level according to the number of metabolic syndrome components. Each bar represents the mean and $95 \%$ confidence interval of adiponectin level. Adiponectin level are increased in parallel with the number of metabolic syndrome components ( $P$ for trend $<0.001$ ). MS metabolic syndrome

regulation of expression, secretion, or excretion of adiponectin is destroyed [30].

Nevertheless, the present analysis indicates that adiponectin level was independently associated with the risk of metabolic syndrome in chronic kidney disease patients after adjustment for confounding factors including eGFR and UACR. Adiponectin is secreted from visceral fat. Therefore, a strong relationship between adiponectin level and metabolic components including triglycerides, HDL-C, and waist measurements might overwhelm the association with renal function. In particular, waist enlargement is the second-most common metabolic syndrome component, followed by glucose. In this analysis, the relationship between adiponectin level and the risk of metabolic syndrome would mostly be influenced by the prevalence of larger-waist subjects. In obese subjects, adiponectin levels were lower despite the fact that adipose tissue is its source [31]. In addition, adiponectin level was demonstrated to be lower in body weight reduction subjects [32]. Waist circumference is not only a simple indicator of obesity but is also related to nontraditional risk factors such as inflammation [33]. The strong relationship between metabolic derangements such as waist circumference or hypertriglyceridemia and adiponectin level suggests that these metabolic factors are overwhelming the association between adiponectin level and low eGFR or albuminuria in patients with chronic kidney disease.

In the end, we found several results. First, serum albumin levels were significantly and independently associated with adiponectin levels in our analysis. In fact, this clear finding has already been reported in several previous investigations [11,34], and the mechanistic linkage have postulated through protein-energy wasting syndrome (PEWS), which is the chief contributor to adverse clinical outcomes in uremic patients [17]. Given that serum albumin levels have been regarded as major markers of either malnutrition or PEWS, the inverse relationship between serum albumin and circulating adiponectin concentrations might be in line with our findings. Second, low hemoglobin levels were independently associated with high adiponectin levels, and these findings have also been reported in several previous investigations [35, 36]. It remains uncertain why low hemoglobin concentrations are independently associated with high circulating adiponectin levels. One plausible explanation is the increased expression of hypoxia inducible factor (HIF), which results from anemia-induced tissue hypoxia. A recent experimental study clearly indicated that HIF-1 activation with a variety of stimuli significantly increases adiponectin expression [37]. Another suggestion is that circulating adiponectin would be chiefly secreted from bone marrow fat, with an inverse correlation between fat mass and circulating adiponectin levels [38]. Considering that marrow adipocyte is a negative regulator of hematopoiesis [39], we would assume an independent relationship between circulating adiponectin and hemoglobin levels.

Several limitations of our study must be acknowledged. First, the study was performed with an analysis of 
cross-sectional data, the causative role of adiponectin on development of metabolic syndrome is still inconclusive. Thus, given the differences in overall outcome between previous studies, further research with a prospective design in this area should be prioritized. Second, in the course of defining metabolic syndrome, the waist circumference was evaluated using Asian criteria. Although there is controversy about defining the waist criteria in metabolic syndrome diagnosis, the Korean Diabetes Association presented Korean waist criteria, which is the same as the Asian criteria in the harmonizing definition. Third, the genetic polymorphism of adiponectin levels was also reported [40], thus the fact that a single ethnicity Korean cohort was used should be considered during interpretation.

\section{Conclusion}

In conclusion, low adiponectin levels were independently associated with the presence of metabolic syndrome in chronic kidney disease patients. The relationship showed linearity throughout the categorical adiponectin levels. A strategy to modulate serum adiponectin might be helpful to improve metabolic derangements in patients with chronic kidney disease.

\section{Authors' contributions}

CYY, YLK, and KHC made conception and design of the study, CYY, YLK, SHH, and $\mathrm{KHC}$ analyzed and interpreted the data; SHH, THY, SAS, WKC, DWC, YSK, $\mathrm{CA}$, and $\mathrm{KHC}$ have collected the data; $\mathrm{CYY}, \mathrm{SHH}$, and $\mathrm{KHC}$ drafted the manuscript and $\mathrm{KHC}$ furthermore revised it critically for important intellectual content; all authors have given final approval of the version to be published; and agree to be accountable for all aspects of the work in ensuring that questions related to the accuracy or integrity of any part of the work are appropriately investigated and resolved. All authors read and approved the final manuscript.

\section{Author details}

${ }^{1}$ Department of Internal Medicine, College of Medicine, Institute of Kidney Disease Research, Yonsei University, 50 Yonsei-ro, Seodaemun-gu, Seoul 120-752, Republic of Korea. ${ }^{2}$ Department of Internal Medicine, Eulji General Hospital, Seoul, Republic of Korea. ${ }^{3}$ Department of Internal Medicine, Gachon University School of Medicine, Incheon, Republic of Korea. ${ }^{4}$ Department of Internal Medicine, Seoul National University Bundang Hospital, Gyeonggi-do, Seongnam, Republic of Korea. ${ }^{5}$ Department of Internal Medicine, Seoul St. Mary Hospital, Catholic University of Korea, Seoul, Republic of Korea. ${ }^{6}$ Department of Internal Medicine, Seoul National University Hospital, Seoul, Republic of Korea.

\section{Acknowledgements}

The authors acknowledge all of the patients who participated in the KNOWCKD and the investigators who took part in data collection. This work was supported by the Research Program funded by the Korea Centers for Disease Control and Prevention (2011E3300300, 2012E3301100, 2013E3301600).

\section{The KNOW-CKD Investigator Group}

Patient Recruitment. Seoul National University Hospital, Curie Ahn, MD (PI), Kook-Hwan Oh, MD (SubPI), Hajeong Lee, MD, Seungmi Lee, RN, Jiseon Kim, RN, and Aram Lee, RN. Seoul National University Bundang Hospital, Dong Wan Chae, MD (SubPI), Seon Ha Baek MD, and Hyun Jin Cho, RN. Yonsei University, Severance Hospital, Kyu Hun Choi, MD (SubPI), Seung Hyeok Han, MD, Tae Hyun Yoo, MD, and Mi Hyun Yu, RN. Kangbuk Samsung Hospital, Kyu-Beck Lee, MD and Young Youl Hyun, MD. The Catholic University of Korea, Seoul St. Mary's Hospital, Yong-Soo Kim, MD and Min Jung Ahn, RN. Gachon University, Gil Hospital, Wookyung Chung, MD, Ji Yong Jung, MD, Youkyoung Jang, RN, and Ji Hye Park, RN. Eulji Medical Center, Eulji
University. Suah Sung, MD, Sung Woo Lee, MD, and Min A Yoo, RN. Chonnam National University Hospital, Soo Wan Kim, MD, Seong Kwon Ma, MD, Eun Hui Bae, MD, Chang Seong Kim, MD, Yong Un Kang, MD, Ha Yeon Kim, MD, and Ji Seon Lee, RN. Inje University, Pusan Paik Hospital, Yeong Hoon Kim, MD, Sun Woo Kang, MD, Tae Hee Kim, MD and A Jin Son, RN.

Polycystic Kidney Disease Research. Seoul National University Boramae Medical Center, Yun Kyu Oh, MD (SubPI), Truewords Dialysis Clinic Young-Hwan Hwang, MD.

Epidemiology and Biostatistics. Department of Preventive Medicine, Seoul National University College of Medicine, Byung-Joo Park, MD, Sue K. Park, MD and Ju Yeon Lee.

Data Coordinating Center. Medical Research Collaborating Center, Seoul National University Hospital and Seoul National University College of Medicine, Joongyub Lee, MD, Dayeon Nam, RN, Soohee Kang, MSc and Heejung Ahn, RN. Central Laboratory. Dong Hee Seo, MD, and Dae Yeon Cho, PhD, LabGenomics, Korea. Biobank. Korea Biobank, Korea Centers for Disease Control and Prevention, Osong, Korea. Korea Center for Disease Control and Prevention. Go Un Yeong, Kim Yeong Taek, Lee Hyejin, Ahn Eun Mi and Jeon Seo Heui.

Competing interests

The authors declare that they have no competing interests.

Ethics approval and consent to participate

The study was performed in accordance with the Declaration of Helsinki and the Internal Review Board at each participating center approved this study. Written informed consent was obtained from all participants in the study.

Received: 8 May 2016 Accepted: 8 November 2016

Published online: 14 November 2016

\section{References}

1. Alberti K, Eckel RH, Grundy SM, Zimmet PZ, Cleeman Jl, Donato KA, et al. Harmonizing the metabolic syndrome a joint interim statement of the international diabetes federation task force on epidemiology and prevention; national heart, lung, and blood institute; american heart association; world heart federation; international atherosclerosis society; and international association for the study of obesity. Circulation. 2009;120:1640-5.

2. Ford ES. Risks for all-cause mortality, cardiovascular disease, and diabetes associated with the metabolic syndrome a summary of the evidence. Diabetes Care. 2005;28:1769-78.

3. Kurella M, Lo JC, Chertow GM. Metabolic syndrome and the risk for chronic kidney disease among nondiabetic adults. J Am Soc Nephrol. 2005; 16:2134-40

4. Yoon C-Y, Lee MJ, Kee YK, Lee E, Joo YS, Han IM, et al. Insulin resistance is associated with new-onset cardiovascular events in nondiabetic patients undergoing peritoneal dialysis. Kidney Res Clin Pract. 2014;33:192-8.

5. Whitehead JP, Richards AA, Hickman IJ, Macdonald GA, Prins JB. Adiponectin-a key adipokine in the metabolic syndrome. Diabetes Obes Metab. 2006:8:264-80.

6. Yamauchi T, Kamon J, Waki H, Terauchi Y, Kubota N, Hara K, et al. The fatderived hormone adiponectin reverses insulin resistance associated with both lipoatrophy and obesity. Nat Med. 2001;7:941-6.

7. Matsuzawa Y, Funahashi T, Kihara S, Shimomura I. Adiponectin and metabolic syndrome. Arterioscler Thromb Vasc Biol. 2004;24:29-33.

8. Pilz S, Horejsi R, Möller R, Almer G, Scharnagl H, Stojakovic T, et al. Early atherosclerosis in obese juveniles is associated with low serum levels of adiponectin. J Clin Endocrinol Metab. 2005;90:4792-6.

9. Hayashi M, Shibata R, Takahashi H, Ishii H, Aoyama T, Kasuga H, et al. Association of adiponectin with carotid arteriosclerosis in predialysis chronic kidney disease. Am J Nephrol. 2011;34:249-55.

10. Park JT, Yoo TH, Chang TI, Lee DH, Lee JH, Lee JE, et al. Insulin resistance and lower plasma adiponectin increase malignancy risk in nondiabetic continuous ambulatory peritoneal dialysis patients. Metabolism. 2011;60:121-6.

11. Menon V, Li L, Wang X, Greene T, Balakrishnan V, Madero M, et al. Adiponectin and mortality in patients with chronic kidney disease. J Am Soc Nephrol. 2006;17:2599-606. 
12. Oh K-H, Park SK, Park HC, Chin HJ, Chae DW, Choi KH, et al. KNOW-CKD (KoreaN cohort study for outcome in patients with chronic kidney disease): design and methods. BMC Nephrol. 2014;15:80.

13. Keys A, Fidanza F, Karvonen MJ, Kimura N, Taylor HL. Indices of relative weight and obesity. J Chronic Dis. 1972;25:329-43.

14. Levey AS, Coresh J, Greene T, Stevens LA, Zhang YL, Hendriksen S, et al. Using standardized serum creatinine values in the modification of diet in renal disease study equation for estimating glomerular filtration rate. Ann Intern Med. 2006;145:247-54.

15. Hara K, Matsushita Y, Horikoshi M, Yoshiike N, Yokoyama T, Tanaka H, et al. A proposal for the cutoff point of waist circumference for the diagnosis of metabolic syndrome in the Japanese population. Diabetes Care. 2006;29:1123-4.

16. Kishida K, Funahashi T, Shimomura I. Adiponectin as a routine clinical biomarker. Best Pract Res Clin Endocrinol Metab. 2014;28:119-30.

17. Kollerits B, Fliser D, Heid IM, Ritz E, Kronenberg F. Gender-specific association of adiponectin as a predictor of progression of chronic kidney disease: the mild to moderate kidney disease study. Kidney Int. 2007;71:1279-86.

18. Stenvinkel P. Adiponectin in chronic kidney disease: a complex and context sensitive clinical situation. J Ren Nutr. 2011;21:82-6.

19. Zoccali C, Mallamaci F, Panuccio V, Tripepi G, Cutrupi S, Parlongo S, et al. Adiponectin is markedly increased in patients with nephrotic syndrome and is related to metabolic risk factors. Kidney Int Suppl. 2003. doi:10.1046/j.1523-1755.63.s84.49.x.S98-102.

20. Chudek J, Adamczak M, Karkoszka H, Budzinski G, Ignacy W, Funahashi T, et al. Plasma adiponectin concentration before and after successful kidney transplantation. Transpl Proc. 2003;35:2186-9.

21. Kamari Y, Shimoni N, Koren F, Peleg E, Sharabi Y, Grossman E. High-salt diet increases plasma adiponectin levels independent of blood pressure in hypertensive rats: the role of the renin-angiotensin-aldosterone system. J Hypertens. 2010;28:95-101.

22. Iwashima Y, Horio T, Kumada M, Suzuki Y, Kihara S, Rakugi H, et al. Adiponectin and renal function, and implication as a risk of cardiovascular disease. Am J Cardiol. 2006;98:1603-8.

23. Cammisotto PG, Bendayan M. Adiponectin stimulates phosphorylation of AMP-activated protein kinase alpha in renal glomeruli. J Mol Histol. 2008;39:579-84.

24. Ohashi K, Iwatani H, Kihara S, Nakagawa Y, Komura N, Fujita K, et al. Exacerbation of albuminuria and renal fibrosis in subtotal renal ablation model of adiponectin-knockout mice. Arterioscler Thromb Vasc Biol. 2007;27:1910-7

25. Yu Y, Bao BJ, Fan YP, Shi L, Li SQ. Changes of adiponectin and its receptors in rats following chronic renal failure. Ren Fail. 2014:36:92-7.

26. Pischon T, Girman CJ, Hotamisligil GS, Rifai N, Hu FB, Rimm EB. Plasma adiponectin levels and risk of myocardial infarction in men. JAMA. 2004;291:1730-7.
27. Kistorp C, Faber J, Galatius S, Gustafsson F, Frystyk J, Flyvbjerg A, et al. Plasma adiponectin, body mass index, and mortality in patients with chronic heart failure. Circulation. 2005;112:1756-62.

28. Anker SD, Ponikowski P, Varney S, Chua TP, Clark AL, Webb-Peploe KM, et al. Wasting as independent risk factor for mortality in chronic heart failure. Lancet. 1997;349:1050-3.

29. Shen YY, Charlesworth JA, Kelly JJ, Loi KW, Peake PW. Up-regulation of adiponectin, its isoforms and receptors in end-stage kidney disease. Nephrol Dial Transpl. 2007;22:171-8.

30. Kintscher $U$. Does adiponectin resistance exist in chronic heart failure? Eur Heart J. 2007:28:1676-7.

31. Arita Y. Reprint of "paradoxical decrease of an adipose-specific protein, adiponectin, in obesity". Biochem Biophys Res Commun. 2012;425:560-4.

32. Yang W-S, Lee W-J, Funahashi T, Tanaka S, Matsuzawa Y, Chao C-L, et al. Weight reduction increases plasma levels of an adipose-derived anti-inflammatory protein, adiponectin. J Clin Endocrinol Metab. 2001;86:3815-9.

33. Festa A, D'Agostino R Jr, Williams K, Karter A, Mayer-Davis E, Tracy R, et al. The relation of body fat mass and distribution to markers of chronic inflammation. Int J Obes Relat Metab Disord. 2001;25:1407-15.

34. Hyun YY, Lee KB, Oh KH, Ahn C, Park SK, Chae DW, et al. Serum adiponectin and protein-energy wasting in predialysis chronic kidney disease. Nutrition. 2016. doi:10.1016/j.nut.2016.06.014.

35. Lewerin C, Johansson H, Lerner UH, Karlsson MK, Lorentzon M, BarrettConnor $\mathrm{E}$, et al. High serum adiponectin is associated with low blood haemoglobin in elderly men: the Swedish MrOS study. J Intern Med. 2015;278:68-76.

36. Aso Y, Suganuma R, Wakabayashi S, Hara K, Nakano T, Suetsugu M, et al. Anemia is associated with an elevated serum level of high-molecularweight adiponectin in patients with type 2 diabetes independently of renal dysfunction. Transl Res. 2009;154:175-82.

37. Natarajan R, Salloum FN, Fisher BJ, Kukreja RC, Fowler AA 3rd. Hypoxia inducible factor-1 upregulates adiponectin in diabetic mouse hearts and attenuates post-ischemic injury. J Cardiovasc Pharmacol. 2008;51:178-87.

38. Hardouin P, Pansini V, Cortet B. Bone marrow fat. Jt Bone Spine. 2014:81:313-9.

39. Naveiras O, Nardi V, Wenzel PL, Hauschka PV, Fahey F, Daley GQ. Bonemarrow adipocytes as negative regulators of the haematopoietic microenvironment. Nature. 2009;460:259-63.

40. Vasseur F, Helbecque N, Dina C, Lobbens S, Delannoy V, Gaget S, et al. Single-nucleotide polymorphism haplotypes in the both proximal promoter and exon 3 of the APM1 gene modulate adipocyte-secreted adiponectin hormone levels and contribute to the genetic risk for type 2 diabetes in French Caucasians. Hum Mol Genet. 2002;11:2607-14.

\section{Submit your next manuscript to BioMed Central and we will help you at every step:}

- We accept pre-submission inquiries

- Our selector tool helps you to find the most relevant journal

- We provide round the clock customer support

- Convenient online submission

- Thorough peer review

- Inclusion in PubMed and all major indexing services

- Maximum visibility for your research

Submit your manuscript at www.biomedcentral.com/submit 